Published in final edited form as:

Int Migr Rev. 2008 ; 42(4): 861-876. doi:10.1111/j.1747-7379.2008.00150.x.

\title{
Health of Immigrants in European countries
}

\author{
Aïda Solé-Auró ${ }^{1}$ and Eileen M. Crimmins ${ }^{2}$ \\ ${ }^{1}$ RISC-IREA Research Group.Department of Econometrics, University of Barcelona. Avda. \\ Diagonal, 690. 08034 Barcelona. Phone: 9340243 18. Fax: 934021821 \\ ${ }^{2}$ Andrus Gerontology Center, University of Southern California, Los Angeles, CA 90089-0191, \\ U.S.A., Phone: 213-740-1707. Fax: 213-740-0787
}

\begin{abstract}
The health of older immigrants can have important consequences for needed social support and demands placed on health systems. This paper examines health differences between immigrants and the native-born populations aged 50 years and older in 11 European countries. We examine differences in functional ability, disability, disease presence and behavioral risk factors, for immigrants and non-immigrants using data from the Survey of Health, Aging and Retirement in Europe (SHARE) database. Among the 11 European countries, migrants generally have worse health than the native population. In these countries, there is a little evidence of the "healthy migrant" at ages 50 years and over. In general, it appears that growing numbers of immigrants may portend more health problems in the population in subsequent years.
\end{abstract}

\section{Keywords}

Immigrants; Mortality; Health; Disability; SHARE

\section{Introduction}

In recent decades, with the development and expansion of the European Union, emigrating within Europe is not as difficult as in the past and international borders are no longer restrictive to many individuals. This has resulted in a dramatic increase in immigration rates for many countries in Europe (Österie, 2007). It is of importance to social planning to understand whether immigrants differ from the native-born population in ways that will affect the demand for social support and health care. This is particularly true for older immigrants who are approaching the age of retirement and the age when health care costs may increase. Our aim is to examine the health of immigrants relative to the native-born populations in the population aged 50 years and older in 11 European countries. Ten of these countries are members of the European Union.

While immigration from within the European Union accounts for some of the immigration to these 11 European countries, movement of people into the Union from poorer countries characterizes a significant portion of European migration over recent decades (Massey et al., 1993). People nearing retirement age generally migrated decades ago as migration is most likely to occur in the early working ages, often motivated by the economic possibilities at the destination (Karras and Chiswick, 1999; Barrell et al., 2006). In general, immigrants have lower socio-economic status than the populations into which they move (Ringbäck et al., 1999). The relative health of immigrants is less clear a priori. Some evidence from both the United States and Europe suggests that immigrants may be healthier than might be expected given their social status (Razum and Twardella, 2002; Jasso et al., 2004); on the other hand, other research in Europe has found mixed patterns of immigrant health depending on country of origin (Gadd et al., 2006; Sundquist and Li, 2006). 


\section{Background}

Between 1950 and 1982, the number of foreign residents increased from 3.1 to 11.2 million in the traditional receiving countries (Belgium, France, Germany, Luxembourg, the Netherlands, Sweden and Switzerland), which accounted for 70-80 percent of all European immigrants over the three decades (Maillat, 1987). In the early part of this period large numbers of immigrants were still being resettled after World War II. There was also significant immigration from once colonized countries in Asia, Africa and the Middle East to the original colonial power (Fassmann and Munz, 1992; Zimmermann, 1994). By the 1960s, there was extensive migration from Southern to Northern Europe. Spain and Portugal were the most important European emigration countries, followed by Greece and Yugoslavia; Sweden, France, the United Kingdom and Switzerland were the main poles of attraction. In the 1980s, the Southern Europe countries themselves became places of immigration. Africa generated new surges of immigration to Greece, Italy, Spain and Portugal as well as to traditional receiving countries (Salt, 1989). Most of the people whom we study here, now 50 and over, would have migrated to the countries where they are now living in their prime working years or before 1980. Since that time, migration from Eastern Europe has been a significant source or immigrants for many countries in the European Union.

Many recent studies in the United States have noted that immigrants from Mexico have better health than non-immigrants or better than expected health given their social status (Cho et al., 2004; Palloni and Arias, 2004; Crimmins et al., 2007). The relatively good health of the Hispanic immigrant population is known as the "Hispanic paradox". The paradox arises from the fact that a socioeconomically deprived population has health as good as that of the mainstream population. European researchers have also noted an "Immigrant paradox" which describes the better than expected health of some immigrant populations (Ronellenfitsch and Razum, 2004).

In Europe the observed health differences between native-born and immigrants vary by country of study and origin of migrants and also gender. In Sweden male immigrant groups appear to have worse mortality and heart disease than Swedes but better than the populations they came from (Gadd et al., 2003; Sundquist et al., 2006). The relative health of immigrant populations, however, may depend on area of origin. Marmot (1984) reports that in England and Wales, migrants from Europe have better health than the native-born, but female migrants from the Caribbean and Africa had higher mortality than natives. In France, male immigrants from Morocco have lower mortality than native-born men but women from Morocco have higher mortality than French women (Khlat and Courbage, 1996).

Jasso et al. (2004) have emphasized the effects of both selectivity and acculturation on immigrant health. Initially, immigrants may be selected for good health from the population they are leaving; but as time since migration increases, their health may become more like the population in the country where they live (Williams, 1993). So the health of immigrants relative to the native population may depend on the age at migration and the age when health is examined. For instance, immigrants from Eastern Europe to Germany had better health than native West Germans initially; however, five years after immigration the health differences disappeared (Stronks, 2003) and at the same time the socio-economic disadvantage of immigrants compared to native Germans had diminished. This reduction in differences may occur because some health conditions appear later in life and would not be related to the propensity to migrate or because over time the immigrants become more like the population at their destinations in socioeconomic status and health-related behaviors (Lopez-Gonzalez et al., 2005; Stronks, 2003). 
There are many reasons why there may not be a consistent pattern of health differences between immigrants and native-born population across time and place. First, migration occurs for a variety of reasons and immigrant characteristics may differ with those reasons and according to the obstacles to be overcome in migrating. It is also true that differentials between immigrants and the native populations may differ across dimensions of health (Jasso et al, 2004; Hayward et al., 2007). For instance, there may be differentials in disability but not mortality because immigrants who are ill may return to their native countries for treatment or to die (Palloni and Arias, 2004). It is also possible that differences in use of health care resulting from lack of access or language barriers could result in differences in the progression of health problems as well as reporting of health problems. For example, if immigrants do not use the medical system in the same way as the native population, they may not know they have diseases. In addition, if immigrants are less likely to be treated for some conditions, they could die more quickly and paradoxically have a lower prevalence of a condition than the surviving population. It is also possible that data quality may differ between immigrants and the native population (Smith and Bradshaw, 2006).

There are many ways that immigrants are likely to differ from native populations that may be related to health differentials that are important in understanding observed differentials. Immigrants tend to have lower socioeconomic status than the populations into which they move because they are moving for improved job opportunities. Worse health could be due to the psychological stress of living in a new environment or stress resulting from discrimination in the new living situation (Silveira et al., 2002). The foreign born are also less likely to have adequate health care coverage or familiarity with and established connections to health care systems (Carrasquillo et al, 2000; Tovar et al., 2007). Health behaviors may also affect population health differences. Immigrants can have healthier or less healthy life styles than native-born members of the population (Carrasco-Garrido et al. 2007).

Our study affords a new examination of disparities in health and health behaviour between immigrants and the native-born population in 11 different European countries. We are interested in whether there are systematic health differences between these groups and whether differences are a reflection of socioeconomic differences.

\section{Data and Methods}

\section{Data}

We use data from the Survey of Health, Aging and Retirement (SHARE) which provides information on health, socio-economic status and social and family networks of individuals aged 50 and over in participating countries. The first wave of this survey was collected in 2004/2005 in 11 European countries; additional waves are being planned and additional countries are now being added. While this is a multi-country project, countries conducted their own national surveys using a common questionnaire translated into the appropriate languages; The Mannheim Research Institute for the Economics of Aging in Germany coordinates this collaborative effort. Our study includes information from the eleven countries, which provide a balanced representation of the various regions in Europe, ranging from Scandinavia through central Europe to the Mediterranean. The names of the individual countries are shown in Table 1. In comparing countries we need to be mindful of some differences in the quality of the surveys. Household response rates vary markedly across the countries from a low of $39 \%$ in Switzerland to a high of $81 \%$ in France; and individual response rates range among $74 \%$ in Spain to a high of $93 \%$ in France (SHARE, 2007). 


\section{Measuring Immigration Status, Health and other variables in SHARE}

Each survey respondent indicates whether he/she was born in the country of residence where the survey is taking place. This response is used to divide the residents of each country into the native-born and the foreign-born or immigrants. Individuals born outside the country where they are interviewed are asked what year they came to the country. While people indicate where they were born, these data are not yet available for analysis.

The SHARE datasets contain comparable indicators of disease, disability and functioning, as well as health behaviors. We use three indicators of problems with functioning and disability: self-reported difficulty performing at least one of 10 tasks related to mobility, strength and endurance (Nagi, 1976), difficulty doing at least one of 6 activities of daily living (ADLs) indicating ability to care for oneself, and difficulty with at least one of 7 instrumental activities of daily living (IADLs) needed for independent living. The ten indicators of functioning ability include walking one block, climbing several flights of stairs, climbing one flight of stairs, sitting for about 2 hours, getting up from a chair, lifting or carrying weights over $10 \mathrm{lbs}$, stooping, kneeling or crouching, picking up a dime from a table, reaching or extending arms and pulling or pushing large objects. ADL functions include walking across a room, getting in and out of bed, bathing or showering, eating (such as cutting up your food), dressing (including putting on shoes and socks) and using the toilet (including getting up or down). IADL abilities include using a map to figure out how to get around in a strange place, preparing a hot meal, shopping for groceries, making telephone calls, taking medications, doing work around the house or garden and managing money, such as paying bills and keeping track of expenses.

In addition information on the presence of 7 chronic diseases is reported in response to the question "Has a doctor ever told you that you had any of the following conditions?" Chronic medical measures include high blood pressure, diabetes, cancer, lung disease, heart disease, stroke and arthritis. We use a variable indicating the presence of 2 or more of these chronic diseases in our analysis. Self-perceived health is assessed using the question "Would you say your health is excellent, very good, good, fair or poor?" We group self-perceived health into two categories: good or very good health and less than good health. Each of the health indicators is coded as a dichotomous variable.

We also examine indicators of weight and smoking behavior. Information on height and weight is converted into body mass index (BMI) which is categorized as overweight (BMI $>=25)$ or not overweight. Smoking is coded as being a current smoker or not.

In order to examine how the socioeconomic status (SES) of immigrants is related to their relative health status, we control for education in our analysis. Education is the most appropriate indicator of SES when one is examining people across a wide range of ages and across multiple countries. Since education systems vary across the countries, SHARE provides an equivalence scale based on the International Standard Classification of Education (ISCED) designed for UNESCO in the early 1970's (UNESCO, 1997). Education is categorized into 7 categories: pre-primary education, primary education (first stage of basic education), lower secondary education (second stage of basic education), upper secondary education, post-secondary non tertiary education, first stage of tertiary education (not leading directly to an advanced research qualification) and second stage of tertiary education (leading to an advanced research qualification). To make this a continuous variable we code each category at its midpoint to indicate years of education.

We also examine differences in labor force status of immigrants and non-immigrants using responses to the following question, "How would you describe your current situation?" retired, employed or self-employed (including working for a family business), unemployed, permanently sick or disabled and homemaker. We group respondents into two categories: 
employed or not employed. Moreover, we examine differences in health care usage among immigrants and the native-born population that might be relevant to their reports of diseases. Health care usage is reported using the following question, "During the last 12 months, about how many times in total have you seen or talked to a medical doctor about your health?" We group health care usage into one or more visits versus no visits.

\section{The Sample}

Table 1 shows the size and composition of the SHARE sample in each country. The data used for this analysis include information from 27,444 individuals living in 11 European countries who have provided responses for all variables used in the analysis. The sample is composed of 12,552 males (996 immigrants) and 14,892 females (1,224 immigrants). There are 758 individuals eliminated from the sample because of missing data on variables used in the analysis, leaving an analytic sample of 26,686 individuals. Those who are excluded from our analysis are significantly more likely to be female (70.7\%) than included individuals (53.8\%). The average age of those non-included is older (69) than that of the non-missing (65). Among the 2,220 immigrants, $3.1 \%$ have missing information. If we compare missing and non-missing immigrants in terms of age, those who are excluded from our sample are significantly older (average 68) than included individuals (average 64). Also, the missing immigrants are significantly more likely to be female than the non-missing immigrants.

The percentage of immigrants in the population age 50 and over in each country ranges from 18.7 percent in Germany to 1.5 percent in Italy (Table 1). The percentage of immigrants is highest in Northern European countries - Germany, France and Switzerland; and lowest in Southern European countries - Italy, Spain and Greece. In all countries, the number of immigrant females exceeds that of immigrant males; the countries with the highest proportion of female immigrants are Italy, Greece and Spain. Since this is an older group, the preponderance of women may reflect mortality differences more than past differences in immigration. Immigrants are most likely to be citizens in Italy, Greece and Germany and least likely in Belgium, Spain and Switzerland.

While the sample ranges in age from 50 to 104, the average age of the entire sample is 65 years old. However, immigrants are a year younger on average (64). Immigrants from Austria, Belgium, Germany and Greece have a higher mean age than non-immigrants in their countries (data not shown). The non-immigrant individuals in the seven remaining countries are older on average than the immigrants. The difference in mean age between immigrants and nativeborn populations ranges from 5.5 years to less than one year. We also indicate the mean year of migration for immigrants in each country in Table 1. As expected, in most countries the average time of immigration for those who are now in their mid 60s in age was about forty years before the survey in the mid 1960s when they were about 20. There are two notable exceptions to this. In Spain immigrants are much more recent, with an average year of migration of 1980. On the other hand, immigrants in Greece have been there since 1953 on average, 50 years before the survey.

In terms of education, immigrants living in Belgium, France, Germany, Netherlands and Switzerland have significantly less education than the native-born residents (data not shown). On the other hand, the greatest difference is in the other direction in Spain where immigrants have almost 4.5 years more education than non-immigrants. This indicates the tremendous differences in the characteristics of the immigrant population relative to the native-born population across these countries.

Immigrants living in Spain, Denmark, France, Italy, Netherlands and Sweden are more likely to be in the labor force than non-immigrants, perhaps due to the fact that immigrants in these countries are younger than non-immigrants. For example, older immigrants to Spain are twice 
as likely to be working as non-immigrants. On the other hand, immigrants to Germany are less likely to work than non-immigrants.

\section{Methods}

We used logistic regressions to examine the effect of being an immigrant on each of the indicators of health and health behavior. Each country is examined separately. We estimate two models: the first shows the odds ratios indicating the relative likelihood that immigrants are in each poor health category with age and sex controlled. These controls adjust for compositional differences that might affect health independent of immigrant status. Then we add education as a control to see how the odds ratios indicating the link between immigrant status and health are changed with this added control, which adjusts for socioeconomic differences between immigrants and non-immigrants.

\section{Results}

\section{Descriptive Analysis}

First, we examine the variability across countries in the percent of the population reporting each of the health problems (Table 2). The prevalence of functioning problems ranges from just over a third to over half the population (38.7-57.4 percent). The prevalence of ADL limitations ranges from 6.9 to 13.5 percent, IADL disability ranges between 8.6 and 25.6 percent. The percent with at least two chronic diseases varies from a low of 28.2 to a high of 51.1 percent. Spain has the highest prevalence of health problems according to many of these indicators; while Switzerland in many cases has the lowest percentage of its population suffering from these health problems. Overall self-reported health aligns somewhat with these indicators of functioning problems, disability, and disease. The Swiss rate their health the highest with only $20.1 \%$ saying health is less than good. On the other hand, people in Spain and Italy are most likely to rate their health as less that good. Health behaviors also vary across these countries. Denmark, Greece and Spain have the highest levels of current smoking. Overweight is highest in Greece, Spain, Austria and Germany.

Table 3 addresses whether there is a difference between immigrants and the native-born in each country in the likelihood of having each type of health problem, risky behavior and low self-perceived health. Odds ratios from logistic regressions within each country are presented. As indicated above, model 1 is run with controls for age and sex. The interpretation of the results for Switzerland is that immigrants are 2.1 times as likely as non-immigrants to have ADL problems, assuming that the age and sex structure of the migrant and non-migrant populations are the same.

There is no indication that immigrants have fewer functioning problems or less disability than the native populations. All significant differences between immigrants and non-immigrants indicate worse functioning and disability for immigrants. Swiss, Swedish, Danish and Dutch immigrants are more likely to have functioning difficulties than the native population in each of these countries. The relative likelihood is highest in Denmark where the immigrants are almost twice as likely to have functioning problems. As indicated above, Swiss immigrants are twice as likely as the native-born population to have ADL difficulties. In no other country is there a significant difference between immigrants and the native-born in ADL problems.

In two countries, Switzerland and France, immigrants are 1.5 to 2 times as likely to have IADL difficulties as non-immigrants. Because of the nature of IADL activities, these differences may relate to social and cultural integration as well as underlying functioning problems.

Immigrants in Switzerland are 1.5 times more likely to have at least two chronic diseases than non-immigrants. In contrast, Austrian immigrants are one-third less likely to have chronic 
diseases than non-immigrants. This is the one of the only indicators of better health among an immigrant population than a native-born population. Chronic diseases are reported in response to a question whether a "doctor ever told you" about a disease. If immigrants were less likely to go to doctors, they would be less likely to know of a disease. However, when we examine the use of health care by immigrants and non-immigrants we find that it is very similar in most of the countries and it is unlikely to be a source of differential reporting (Table 4). Only in Austria is there a substantial difference in the reports of seeing a doctor in the last year; in Austria, immigrants are about $6 \%$ less likely to report a doctor visit. This may be related to the finding that Austrian immigrants are less likely to report having diseases.

Self-perceived health can be viewed as the individual's self-assessment of the importance of problems with functioning, disability and disease. In five countries, immigrants are more likely to have worse self-perceived health than non-immigrants (Table 3). These are the countries where immigrants have had more functioning problems, disability or disease (Switzerland, Netherlands, Germany, Sweden and France). Only in Spain do immigrants perceive their health to be better than the native-born population.

We also examine differences between immigrants and non-immigrants in smoking and being overweight to see how immigrants differ from the native-born populations in health habits (Table 3). Immigrants in Austria exhibit a 71\% higher likelihood of being current smokers compared to non-immigrants. In all other countries, smoking behavior does not differ significantly between immigrants and the native-born population. Immigrants are more likely to be overweight than non-immigrants in Germany and Sweden and less likely to be overweight in Spain and Italy.

In the second model under each health outcome, we examine the differences between immigrants and non-immigrants adding a control for education in order to see if the worse health of immigrants is due to their lower levels of education or SES. When we include the education variable, the results do not change much; a couple of coefficients become significant and a couple becomes non-significant. Functioning problems are still lower for immigrants than non-immigrants in 4 countries. In terms of IADL, the effect of controlling for education is to raise the difference in IADL difficulties to significance for persons in Denmark. On the other hand, the difference becomes non-significant in France. Controls for education also result in significantly higher levels of chronic diseases among immigrants in Sweden and Spain. Education control also reduces the difference between migrants and non-migrants in Spanish self-perceived health to non-significance. In general, the differences are relatively stable with controls for education meaning that differences in socioeconomic status between immigrants and non-immigrants do not appear to be the cause of health differences.

\section{Discussion}

The debate about the effect of immigrant populations on demands for health and social services has gone on for many years. While we cannot examine the differences between immigrants and the native populations at the time of immigration, we do examine health differences at the ages when health tends to deteriorate and place more demands on the health care system. Where there are differences in health between migrants and non-migrants in these 11 European countries, migrants generally have worse health. In these countries there is little evidence of the "healthy migrant" at ages 50 and over.

Immigrants appear relatively worse off than native-born individuals in terms of self-perceived health and functioning in France, Germany, Netherlands, Sweden and Switzerland. These countries tend to be the countries with the best overall levels of the health indicators for the entire population, that is the countries with good functioning and low levels of ADL and IADL 
problems. For example, Switzerland has the lowest percent with ADL and IADL problems (6.9 and 8.6, respectively) and the highest likelihood of immigrants relative to the native-born population having ADL and IADL difficulties (almost twice as high in both cases). In reverse, Spain has the highest level of ill health according to many of the indicators studied, but immigrants to Spain have lower levels of some health problems than the native-born. For instance, Spain and Italy have immigrants who are less likely than native-born to be overweight. These findings point to the fact that both the health of the native-born population and the health of the immigrants contribute to the observed health differences.

We also addressed the question of whether there were significant differences by country in the health of immigrants. We limited our analysis to immigrants to see if there countries where immigrants appeared to be healthier or less healthy than immigrants in other countries (data not shown). We do not find evidence of differences. For instance, immigrants to Switzerland do not appear to have worse health than immigrants to other countries

Controls for education in our analysis do not affect our results indicating that the worse health of immigrants in these countries is not due to their lower levels of education or SES. In addition, differences between native-born and immigrants in health care use do not appear to be common in these countries. On the other hand, we do not know many ways in which immigrants and native-born might differ. For instance, we do not know how the jobs that people worked over their lives differed. It is possible that immigrants were more likely to perform manual labor than the native-born resulting in the higher levels of functioning loss and disability observed in some countries.

There are some limitations to our results. We must note that migrants observed at one point in time represent those who remain. People may have died at different rates and the group of immigrants remaining may be more or less selected than the native-born population. Some immigrants may have returned to their origins after becoming ill, another selection process relating to observed differences. In addition, there are differences in the response rates to the surveys across countries, which could affect our results. We should note again, that the lowest response levels were in Switzerland. Differential response by people with and without health problems among immigrants and non-immigrants may affect observed differences.

As indicated above, we do not have information on the area of origin of migrants and how that differs across countries. The migration streams during which these European migrants moved differed across the 11 countries. For instance, the Southern European countries of Spain, Greece and Italy were sending immigrants to the Northern counties in the 1960. In the 1980s the characteristics of migrants to European countries changed and many migrants were motivated to move by political conflicts, civil wars, and economic crises in the Middle East, South America and Africa. Migrants to Spain studied here are especially likely to be from these new streams (Massey, 1990). Future research should examine the link between health of migrants and the place of origin.

The results of this study should be useful in expanding our understanding of current health issues facing Europe, and provide baseline information from which policy-makers can predict the impact of growing immigration on the health and social security needs of a growing and aging immigrant population. In general, growing numbers of immigrants may be linked to more health problems in the population in subsequent years.

\section{Acknowledgments}

Support was provided by federal grants from the Spanish Ministry of Education and Science, FEDER grant SEJ2007-63298 and the U.S. National Institutes of Health, grant P30 AG17265. 


\section{References}

Barrell R, Guillemineau C, Liadze I. Migration in Europe. National Institute Economic Review 2006;198:36-39.

Carrasquillo O, Carrasquillo AI, Shea S. Health Insurance Coverage of Immigrants Living in the United Status: Differences by Citizenship Status and Country of Origin. American Journal of Public Health 2000;90(6):917-923. [PubMed: 10846509]

Carrasco-Garrido P, Gil A, Hernández V, Jiménez-García R. Health profiles, lifestyles and use of health resources by the immigrant population resident in Spain. European Journal of Public Health 2007;17:503-507. [PubMed: 17251304]

Cho Y, Frisbie WP, Hummer RA, Rogers RG. Nativity, duration of residence and the health of Hispanic adults in the United States. The International Migration Review New York 2004;38(1):184.

Crimmins EM, Kim JK, Alley DE, Karlamangla A, Seeman T. Hispanic Paradox in Biological Risk Profiles. American Journal of Public Health, Washington 2007;97(7):1305-1310.

Fassmann H, Munz R. Patterns and Trends of International Migration in Western Europe. Population and Development Review 1992;18(3):457-480.

Gadd M, Johansoon SE, Sundquist J, Wändell P. Are the differences in all-cause and coronary heart disease mortality between immigrants in Sweden and in their country of birth? A follow-up study of total populations. BMC Public Health 2006;6:102. [PubMed: 16630338]

Gadd M, Johansson SE, Sundquist J, Wändell P. Morbidity in cardiovascular disease in immigrants in Sweden. Journal of Internal Medicine 2003;254:236-243. [PubMed: 12930232]

Hayward MD, Warner DF, Crimmins EM. Does Longer Life Mean Better Health? Not for Native-Born Mexican Americans in the Health and Retirement Survey. Springer 2007;7:85-95.

Jasso, G.; Massey, SD.; Rosenzweig, MR.; Smith, JP.; Anderson, Norman B. Critical Perspectives on Racial and Ethnic Differences in Health in Late Life. Washington, DC, USA: National Academies Press; 2004. Immigrant Health: Selectivity and Acculturation; p. 227-266.

Karras J, Chiswick CU. Macroeconomic Determinants of Migration: The Case of Germany 1964-1988. International Migration Review 1999;37(4):657-677.

Khlat M, Courbage Y. Mortality and causes of death of Moroccans in France, 1979-91. Population 1996;8:59-94. [PubMed: 12157940]

Lopez-Gonzalez L, Aravena VC, Hummer RA. Immigrant Acculturation, Gender and Health Behavior: A Research Note. Social Forces 2005;84(1):581-593.

Maillat, D. The Future of Migration. Organization for Economic Cooperation and Development (OECD); 1987. Long-Term Aspects of International Migration Flows: The Experience of European Receiving Countries; p. 38-63.

Marmot MG, Adelstein AM, Bulusu L. Immigrant mortality in England and Wales 1970-78. Causes of death by country of birth. Studies on Medical and Population Subjects 1984;47

Massey DS, Arango J, Hugo G, Kouaouci A, Pellegrino A, Taylor JE. Theories of International Migration: A Review and Appraisal. Population and Development Review 1993;19(3):431-466.

Massey DS. The Social and Economic Origins of Immigration. Annals of the American Academy of Political and Social Science 1990;510:60-72.

Nagi SZ. An Epidemiology of disability among adults in the United States. Milbank Memorial Fund 1976;54:439-467.

Österle A. Health care across borders: Austria and its new EU neighbours. Journal of European Social Policy 2007;17(2):112-124.

Palloni A, Arias E. Paradox lost: explaining the Hispanic adult mortality advantage. Demography 2004;41:385-415. [PubMed: 15461007]

Razum O, Twardella D. Towards an explanation for a paradoxically low mortality among the recent immigrants. Tropical Medicine and International Health 2002;7(1):4-10. [PubMed: 11851949]

Ringbäck G, Gullberg A, Hjern A, Rosén M. Mortality statistics in immigrant research: method for adjusting underestimation of mortality. International journal of Epidemiology 1999;28:756-763. [PubMed: 10480707] 
Ronellenfitsch U, Razum O. Deteriorating health satisfaction among immigrants from Eastern Europe to Germany. International Journal for Equity on Health 2004:3-4.

Salt J. A Comparative Overview of International Trends and Types, 1950-80. International Migration Review 1989;23(3):431-56. [PubMed: 12282788]

SHARE (Survey of Health, Aging and Retirement in Europe). 2007 Dec. <http://www.share-project.org/ $>$

Silveira E, Skoog I, Sundh V, Allebeck P, Steen B. Health and well-being among 70-year-old migrants living in Sweden - results from the $\mathrm{H} 70$ gerontological and geriatric population studies in Göteborg. Social Psychiatry and Psychiatric Epidemiology 2002;37:13-22. [PubMed: 11924746]

Smith DP, Bradshaw BS. Rethinking the Hispanic paradox: death rates and life expectancy for US nonHispanic White and Hispanic populations. American Journal of Public Health 2006;96(9):16861692. [PubMed: 16380579]

Stronks K. Public health research among immigrant population: still a long way to go. European Journal of Epidemiology 2003;18(9):841-842. [PubMed: 14561041]

Sundquist K, Li X. Coronary heart disease risks in first - and second - generation immigrants in Sweden: a follow-up study. Journal of Internal Medicine 2006;259:418-427. [PubMed: 16594910]

Tovar JJ, Angel RJ, Eschbach k, Espino DV, Markides KS. Hispanic Established Populations for the Epidemiologic Studies of the Elderly: selected longitudinal findings. Aging Health 2007;3(3):325.

Williams R. Health and length of residence among South Asians in Glasgow: a study controlling for age. Journal of Public Health Medicine 1993;15:52-60. [PubMed: 8471301]

UNESCO Institute for Statistics, International Standard Classification of Education. 1997. <http://www.uis.unesco.org/TEMPLATE/pdf/isced/ISCED_A.pdf>

Zimmermann KF. European migration: Push and pull. The World Bank Research Observer 1994;310 


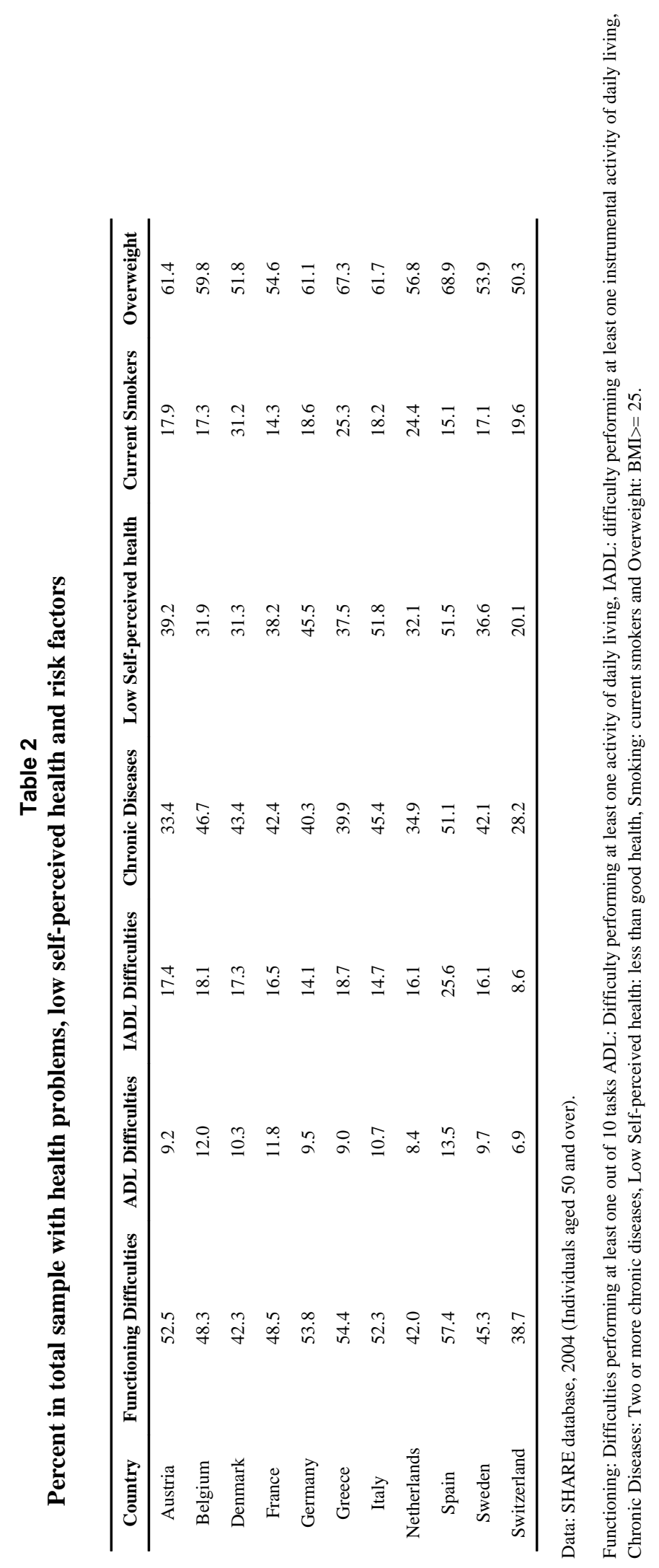

Int Migr Rev. Author manuscript; available in PMC 2010 November 1. 


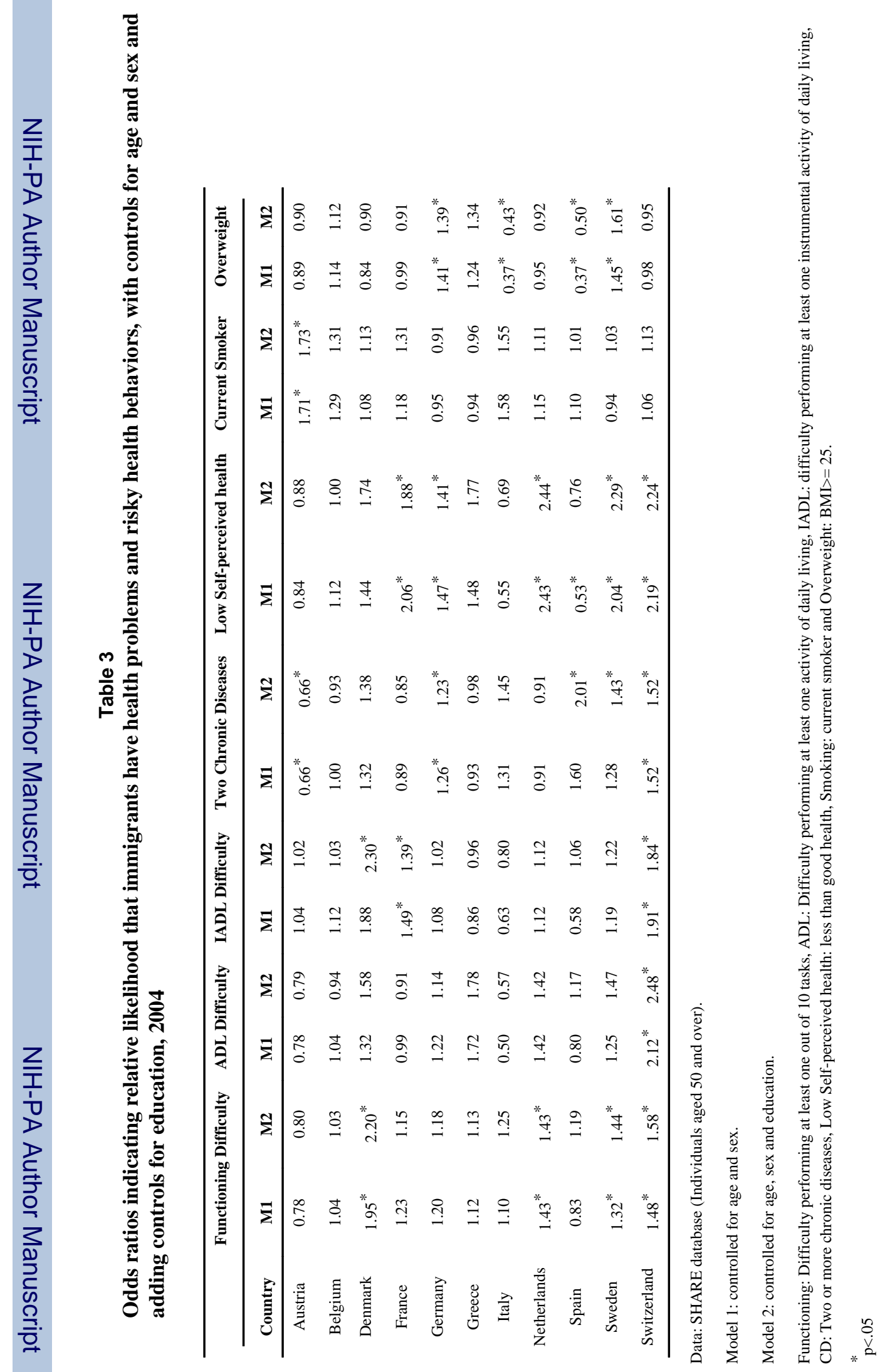


Table 4

Percent seeing doctor in last 12 months

\begin{tabular}{cccc}
\hline Country & Immigrants & Native-born (NB) & Difference (Immigrants - NB) \\
\hline Austria & 80.4 & 86.3 & -5.9 \\
Belgium & 93.1 & 92.7 & 0.4 \\
Denmark & 87.5 & 81.3 & 6.2 \\
France & 94.1 & 93.5 & 0.6 \\
Germany & 92.5 & 92.1 & 0.4 \\
Greece & 77.4 & 78.7 & -1.3 \\
Italy & 81.8 & 83.9 & -2.1 \\
Netherlands & 85.1 & 81.3 & 3.8 \\
Spain & 87.7 & 88.9 & -1.2 \\
Sweden & 77.1 & 77.3 & -0.2 \\
Switzerland & 85.7 & 84.0 & 1.7 \\
\hline
\end{tabular}

Data: SHARE database (Individuals aged 50 and over).

* significantly differed from native-born at the .05 level. 